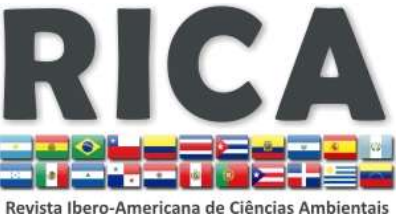

Journals Homepage:

www.sustenere.co/journals

\section{ANÁLISE DO POTENCIAL DE REUTILIZAÇ̃̃O DOS RESÍDUOS PROVENIENTES DE PODA, MUNICÍPIO DE PALMAS, TOCANTINS}

\section{RESUMO}

A destinação geralmente dada aos resíduos de biomassa provenientes da poda depositando-os em aterros e lixões não se mostra sustentável e adequada, pois impossibilita a utilização do seu poder calorífico e do teor de matéria orgânica que podem retornar ao solo. Baseado na potencialidade de utilização desses resíduos o objetivo deste trabalho foi realizar um levantamento da situação e a destinação final desses resíduos em Palmas (TO), quantificando-os e analisar a viabilidade técnicoeconômica de novas alternativas de tratamento. No município de Palmas (TO) estima-se que o resíduo de poda coletado equivale a 1301 ton/ano, 108 ton/mês e 3,61 ton/dia. A produção desses resíduos tem um crescimento de mais $50 \%$ a.a., para o ano de 2014 estimou-se em 8396,17 ton/ano e 23 ton/dia. A receita bruta estimada foi de $\mathrm{R} \$ 1.478 .400,00$ para a Usina de Briquetes e $\mathrm{R} \$ 2.183 .004,81$ para a Usina de Compostagem. Em relação ao custo de produção obteve-se R $\$$ $88,74 /$ ton do composto e $\mathrm{R} \$ 101,29 /$ ton de briquetes, valores menores que o preço de venda encontrando no mercado, o que torna viável a produção e comercialização dos mesmos. No cenário atual é interessante estudar uma possível inclusão das Associações de catadores e/ou de horticultores do município nessas indústrias e uma análise da perspectiva de mercado de ambos os produtos na região.

PALAVRAS-CHAVES: Resíduos Sólidos Urbanos; Aproveitamento da Biomassa; Viabilidade Técnico-Econômica.

\section{STUDY OF THE POTENTIAL FOR REUSE OF PRUNING WASTE FROM MUNICIPALITY OF PALMAS, TOCANTINS}

\section{ABSTRACT}

The allocation usually given to biomass residues from pruning depositing them in landfills and dumps does not seem sustainable and appropriate therefore preclude the use of its calorific value and organic matter content that can return to the soil. Based on the potential use of such wastes the objective of this study was to survey the situation and the final disposal of such waste in Palmas (TO), quantify and analyze the technical and economic feasibility of new treatment alternatives. In the city of Palmas (TO) is estimated that the waste collected pruning equals 1301 tons year, 108 ton / month and 3.61 ton / day. The production of such waste has a growth of over $50 \%$ pa, for the year 2014 was estimated at 8396.17 ton / year and 23 ton / day. Estimated gross revenue was $R \$ 1,478,400.00$ for Briquettes Plant and $R \$$ $2,183,004.81$ for the Composting Plant. Regarding the cost of production was obtained $\mathrm{R} \$ 88.74$ / ton of compost and $\mathrm{R} \$ 101.29$ / ton of briquettes, lower values than those found in the national market for the products, which makes feasible the production and marketing of thereof. In the present scenario it is interesting to study the possible inclusion of Associations of scavengers and / or gardeners in these industries and the municipality to analyze the perspective of both products in the regional market.

KEYWORDS: Utilization of Biomass; Feasibility Technical-Economic.
Revista Ibero-Americana de

Ciências Ambientais, Aquidabã, v.6, n.1, Dez 2014, Jan, Fev, Mar, Abr, Mai 2015.

ISSN 2179-6858

\section{SECTION: Articles}

TOPIC: Saneamento e Tratamento de Resíduos

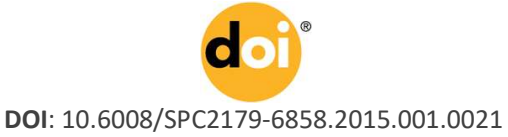

Paula Raquel Barreto Rodrigues Universidade Federal do Tocantins, Brasil http://lattes.cnpq.br/5080061539701821 paularaquel.br@hotmail.com

Aurélio Pessôa Picanço

Universidade Federal do Tocantins, Brasil http://lattes.cnpq.br/5376510759690094 aureliopicanco@uft.edu.br

Juan Carlos Valdés Serra

Universidade Federal do Tocantins, Brasil http://lattes.cnpq.br/0422938566456925 juancs@uft.edu.br

Emerson Adriano Guarda

Universidade Federal do Tocantins, Brasil http://lattes.cnpq.br/932512870212630 emersonprof@uft.edu.br

Amitai Silva Lima Junior Universidade Federal do Tocantins, Brasil http://lattes.cnpq.br/5065965469024627 amitai-jr@hotmail.com

Received: 18/08/2014

Approved: 14/10/2015

Reviewed anonymously in the process of blind peer.

\section{Referencing this:}

RODRIGUES, P. R. B.; PICANÇO, A. P.; SERRA, J. C. V.; GUARDA, E. A.; LIMA JUNIOR, A. S.. Análise do potencia de reutilização dos resíduos provenientes de poda, município de Palmas, Tocantins. Revista lberoAmericana de Ciências Ambientais, Aquidabã, v.6, n.1, p.269-284, 2015. DOl:

http://dx.doi.org/10.6008/SPC2179$\underline{6858.2015 .001 .0021}$ 


\section{INTRODUÇÃO}

Umas das grandes preocupações da sociedade moderna é a destinação dos resíduos e lixo gerado pela atividade humana. O destino dado ao lixo gerado pela população é questão de saúde pública e ambiental, assim como de cidadania e respeito ao espaço de todos. Os sistemas de limpeza urbana têm como objetivo afastar o lixo da população e dar-lhe um destino adequado (SANTOS \& ROCHA, 2010).

Os resíduos de galhadas por longo tempo foram depositados em lixões e aterros sanitários, impossibilitando a utilização do seu poder calorífico e do teor de matéria orgânica que podem retornar ao solo na forma de composto. Dessa forma a destinação convencionalmente dada aos resíduos de poda não se mostra sustentável e adequada (PMF, 2012). Para De Angelis et al. (2007) a reutilização e reciclagem de resíduos gerados pela arborização urbana podem ser de muito proveito, abrindo novos caminhos para um gerenciamento mais adequado. O presente trabalho tem como objetivo avaliar a situação e a destinação atual dos resíduos orgânicos provenientes de poda de arvores, jardins e roçadas públicas de Palmas, Estado do Tocantins. Assim como, quantificar tais resíduos e analisar a viabilidade técnico-econômica de novas alternativas de tratamento ambientalmente adequadas para o município de Palmas (TO).

\section{REVISÃO TEÓRICA}

\section{Classificação dos Resíduos e Limpeza pública}

Segundo a Lei $\mathrm{n}^{\circ}$ 12.305, de 02 de agosto de 2010, que Institui a Política Nacional de Resíduos Sólidos, a definição de resíduo sólido é todo material, substância, objeto ou bem descartado resultante de atividades humanas em sociedade, a cuja destinação final se procede, se propõe proceder ou se está obrigado a proceder, nos estados sólido ou semissólido. Para Freitas (2006), Philippi Jr. e Aguiar (2005), a classificação que os RS recebem é determinante para se estabelecer quais as melhores formas de tratamento e disposição final que deve ser adotada. Os resíduos sólidos (RS) são classificados de acordo com sua origem, segundo a NBR 10.004 (ABNT, 2004) como qualquer material encontrado no estado sólido e semi-sólido resultantes das atividades industriais, domésticas, hospitalares, comerciais, agrícolas, de serviços e de varrição, abrangendo ainda os lodos originados de sistemas de tratamento de água, de equipamentos e instalações de controle de poluição, e determinados líquidos inviáveis para o lançamento na rede pública de esgotos ou corpos de água.

D’Almeida et al. (2000) citado por Costa et al. (2012) define aos resíduos sólidos urbanos (RSU) como sendo o conjunto de detritos gerados em decorrência das atividades humanas nas áreas urbanas. Dentre eles os de origem domiciliar, comercial, das atividades industriais e prestações de serviços, e os de serviços de limpeza pública urbana. O Resíduo Público é aquele originado dos serviços de limpeza pública urbana como: varrição, praias, galerias e bocas de lobo, 
córregos, terrenos, restos de podas, carcaças de animais, feiras livres, etc (BRASIL, 2010; IBAM, 2001).

A responsabilidade dos serviços de limpeza pública urbana é dos municípios (MELO et al., 2011; IBAM, 2001; GRIPPI, 2001). De acordo a Constituição Federal, artigo 30, parágrafo $5^{\circ}$, delibera que, compete aos Municípios organizar e prestar os serviços públicos de interesse local seja diretamente ou sob-regime de concessão ou permissão. A destinação adequada dos resíduos públicos tem como objetivo minimizar riscos à saúde pública, manter a cidade limpa e prevenir enchentes e assoreamento e poluição de rios (BRAND et al., 2002; IPT/CEMPRE, 2000). Para Grippi (2001), os sistemas de limpeza urbana, devem afastar o lixo da população e dar-Ihe um destino ambiental e sanitário adequado.

\section{Geração e Manejo dos Resíduos Públicos}

Dentre as grandes preocupações atuais está o destino dado aos resíduos e lixos originados das atividades humanas. Para Philippi Júnior e Aguiar (2005), a produção de resíduos sólidos faz parte do cotidiano do ser humano. Porém, o aumento da população humana, forma e ritmo da ocupação desses espaços e consumo cada vez mais rápidos de bens têm transformado isto num problema. Melo et al. (2011) afirma que o aumento da produção de resíduos sólidos urbanos provoca maior pressão sobre sua disposição final e a escassez de áreas para esse fim, de tal modo, que cabe ao poder público municipal administra-los da melhor forma possível. Sendo considerado como um método seguro de disposição dos resíduos o Aterro Sanitário ainda encontra como fator limitante para sua aplicação o fato de necessitar de área significativamente grande para operar. Na maior parte dos centros urbanos isto demanda um custo elevado de aquisição ou desapropriação, para a administração pública municipal (CASTRO, 2008).

Os resíduos de poda geram grande volume de resíduos, que implica em um amplo problema na hora de seu descarte, por não aceitar compactação, ocupa maior volume, consumindo espaço útil do aterro, reduzindo sua capacidade e ampliando seus custos operacionais (SILVA et al., 2009). Dessa forma tal destinação dada aos resíduos não se mostra sustentável e adequada, pois não permite o aproveitamento do potencial contido na biomassa vegetal (PMF, 2012). Geralmente no Brasil, os galhos mais grossos são serrados e utilizados como lenha, os demais resíduos são dispostos nos aterros, diminuindo sua vida útil, ou então colocados em áreas específicas, onde ficam estocados, não raro dando origem a incêndios (FERNANDES et al., 2001).

\section{Alternativas de Uso de Resíduos Vegetais}

No cenário atual há uma crescente demanda por tecnologias que promovam o reaproveitamento, a reciclagem e a disposição final apropriada de resíduos, associada à demanda energética mundial e ao apelo por energias limpas e renováveis (FARAGE, 2009). Atualmente 
percebe-se que estão sendo utilizados biocombustíveis, a partir da biomassa vegetal em associação com combustíveis fósseis, como forma de reduzir problemas ao meio ambiente (PETROBRÁS, 2009). Conforme Cortez (2011) os resíduos de poda podem ser utilizados sem aproveitamento energético e com aproveitamento energético. As aplicações para o aproveitamento não energético podem ser: a reutilização por meio de atividades de artesanato, obras de arte, entre outros e; compostagem. As aplicações energéticas estão relacionadas aos processos físicos (briquetagem e peletização), termoquímicos (combustão, incineração, pirólise, gaseificação) e biológicos (digestão anaeróbia).

De acordo com Dourado e Silva (2010) a prática de compostagem diminui o volume de lixo coletado, aumenta tempo de vida útil de aterros, evita poluição visual, produzindo terra vegetal ou matéria seca. Considerada uma técnica de valorização e o reaproveitamento de matéria orgânica, a compostagem gera um produto estabilizado que pode ser aplicado no solo com diversos benefícios sobre os fertilizantes químicos (PMF, 2012). Regulamentado pelo Ministério da Agricultura, Pecuária e Abastecimento, o composto, desde que atenda a determinados condicionamentos, já pode ser considerado como fertilizante orgânico, o que pode vir a incentivar a sua utilização por parte dos agricultores (CASTRO, 2008).

Compostagem é um processo biológico, aeróbio e controlado, de transformação de resíduo orgânico em húmus, desenvolvido por diversos microrganismos envolvendo duas fases distintas, sendo a primeira de degradação ativa (termofílica) e a segunda de maturação; onde é obtido o composto orgânico estável, de coloração escura, conhecido por húmus, passível de ser aplicado ao solo para reposição de nutrientes e matéria orgânica (MOURA et al., 2009).

São atividades de rotina de uma usina de compostagem: a trituração do material; montagem das leiras; aeração das leiras, revirando-as manualmente ou de forma; irrigação das pilhas quando é necessário; limpeza nos espaços entre as leiras e peneiramento do composto pronto na peneira rotativa (SOBRAL \& MAGALHAES, 2009). Cortez et al. (2008) afirma que o aumento da viabilidade econômica é diretamente proporcional à quantidade de composto produzido, e inversamente, ao tempo de decomposição da matéria orgânica. Por isso, a utilização de ativadores comerciais podem acelerar o processo de maturação do composto e tornar a compostagem mais atrativa.

De acordo com Quirino (2004) todo resíduos de origem vegetal pode ser compactado pela briquetagem e tem como vantagens, a geração de emprego e renda, além de retirar do meio ambiente os resíduos poluidores, dando-Ihes uma função rentável. O reaproveitamento energético dos resíduos lignocelulósicos por meio da briquetagem surge como processo tecnológico alternativo de aproveitamento desses resíduos (FARAGE, 2009). O processo consiste em compactação do resíduo triturado sob alta pressão e temperatura resultando em um produto com dimensões padronizadas e elevado peso específico (FARAGE, 2009; MORAIS et al., 2007).

O Briquete é usualmente utilizado para a queima em fornos, caldeiras, aquecedores, torradores, uso doméstico em lareiras e outros similares, devido ao seu elevado poder calorífico (SAIDUR, 2011). Esse material pode ter até seis vezes mais eficientes que a lenha, em poder 
calorífico (IPAISSU, 2014). Os resíduos passam por homogeneização, tanto da composição quanto do tamanho de partícula, há adição de um aglomerante, quando necessário (MORAIS et al., 2007) e depois a compactação. Albuquerque (1997) relata que o processo mecânico gera um aquecimento, que provoca a "liquefação" da lignina presente, que atua como agente aglomerante, dispensando a adição de outro aglutinante, para briquetes a partir de resíduos vegetais ou lignocelulósicos. Os resíduos após briquetagem apresentam concentração energética por volume superior ao inicial; aumento da densidade do resíduo melhorando o armazenamento dos resíduos; melhores condições de transportes; redução dos custos com transporte e armazenamento e; aumento da eficiência energética (FARAGE, 2009; RODRIGUES et al., 2002).

\section{Viabilidade para Novas Alternativas de Tratamento dos Resíduos}

Ainda que a geração de resíduos se apresente como um problema dos processos produtivos, pensando em princípios ecológicos o resíduo de uma atividade pode ser matéria-prima ou fonte energética para outros processos (GOMES \& PIMENTA, 2010). Júnior (2010) ressalta que o desperdício da energia é perceptível, pois, ainda 'joga-se fora' resíduos em condições ambientalmente inapropriadas e perdesse a energia que poderia ser gerada a partir deles. Dentro do cenário atual torna-se importante o desenvolvimento de alternativas energéticas ao suplemento de energia tradicional que, levem desenvolvimento sustentável. O que precisa ser analisado principalmente é a questão da viabilidade técnico-econômica associada à implantação da possível alternativa (SILVA, 2007).

A viabilidade econômica de instalação de uma fábrica está relacionada com a disponibilidade de matéria-prima, a qualidade desse material, as distâncias de transporte, as tarifas de energia elétrica e, principalmente, a capacidade instalada da fábrica (COUTO et al., 2004). Segundo Cortez et al. (2008), o destino mais nobre para resíduos orgânicos é a compostagem, que tem como objetivo fundamental a valorização e o reaproveitamento dessa matéria, gerando um produto estabilizado com vários benefícios sobre os fertilizantes químicos. $A$ análise econômica desse processo pode ser realizada a partis dos gastos com a produção do composto e a sua viabilidade no mercado.

Conforme Silva (2007), o briquete tem competindo diretamente com a lenha e o carvão vegetal, mas os fabricantes de briquetes não têm produto suficiente para atender a esse mercado em sua totalidade. Um estudo realizado pelo mesmo autor demonstrou que maioria dos comerciantes não tem preferências pelo tipo e nem a origem da lenha, sendo o fator determinante na decisão de compra a disponibilidade do produto, em segundo lugar o preço e a qualidade. Dessa forma, a relação de concorrência entre a lenha e os produtos compactados mostra possibilidade de novos produtos no mercado. 


\section{METODOLOGIA}

Para alcançar os objetivos propostos foi necessário um levantamento de dados, a solicitação de informações ocorreu junto à Secretaria Municipal de Infraestrutura e Serviços Públicos (SEISP), do município de Palmas (TO). E ainda pesquisa exploratória de campo com o objetivo de obter dados que demonstrassem a situação e a destinação final dada aos resíduos gerados no serviço de poda, roçagem e varrição pública no município. O presente estudo não considera os resíduos coletados, transportados e dispostos irregularmente.

O Município de Palmas, no Estado do Tocantins, é constituído 228.332 habitantes e possui forte crescimento populacional e econômico. O Município localiza-se na região central do estado do Tocantins, ocupa uma área de 2.218,943 km² (IBGE, 2010). A área urbana do município de Palmas abrange as regiões do Plano Diretor, Taquaralto, Taquari, Aurenys e os distritos de Taquaruçu e de Buritirana, localizados ao longo da rodovia TO-030. Para desenvolvimento deste trabalho foi tomado para estudo a área urbana do município de Palmas, Tocantins. Observa-se na Figura 1 a localização do município de estudo.

Os dados obtidos dos resíduos de galhadas gerados são referentes à série histórica dos anos de 2008 a 2013. Com os resultados referentes à produção, estimou-se a taxa de crescimento anual e a produção esperada para o ano de 2014. Assim foi possível medir a capacidade necessária de processamento desses resíduos para as Usinas de Briquetagem e Compostagem. A viabilidade técnico-econômica fundamenta-se nos estudos realizados por Felfli et al. (2004), Silva (2007), Farage (2009) e Gomes e Pimenta (2010). Foram calculados os investimentos iniciais, os custos operacionais fixos e variáveis, o Lucro Operacional, Ponto de Equilíbrio e Grau de Alavancagem Operacional. Considerando os dados reais da geração dos resíduos e possíveis tratamentos criou-se 2 (dois) cenários a serem analisados: Usina de compostagem; Fábrica de compactação de resíduos para produção de briquetes.

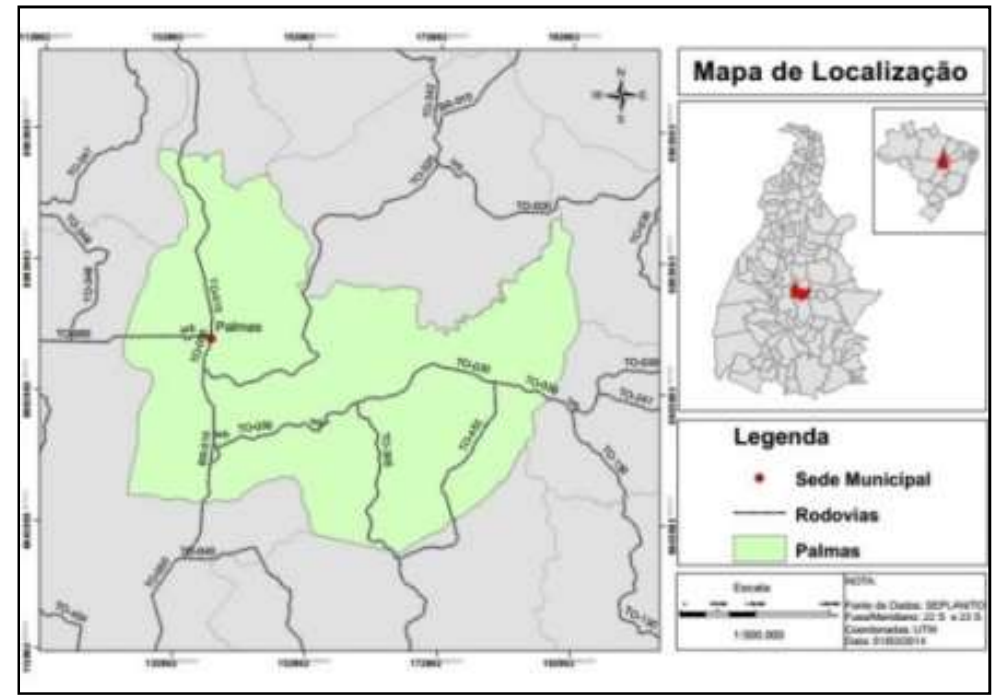

Figura 1: Mapa de localização da área de estudo, município de Palmas (TO).

Baseado na metodologia de Silva (2007) e Gomes e Pimenta (2010), inicialmente foram escolhidos o processo e os equipamentos que seriam utilizados no tratamento dos resíduos; em 
seguida, foi feito um estudo de caso da viabilidade econômica de cada cenário. Foram calculados os investimentos iniciais, a estrutura de custos operacionais fixos e variáveis e os índices técnicoeconômicos de cada Usina. O ponto de equilíbrio operacional pode ser descrito pela equação 1 (MACHADO, 2002 citado por FEFLI, 2004):

$$
P E=\frac{C F}{(L O+C F)}=\frac{C F}{(R B-C V)}
$$

Onde:

$R B=$ Receita Bruta;

$C F=$ Custos fixos;

$\mathrm{CV}=$ Custos variáveis;

$L O=$ Receita Bruta;

$P E=$ Ponto de Equilíbrio.

Com isto é possível calcular o Lucro Operacional (LO) e o Grau de Alavancagem Operacional (GAO) pelas equações 2 e 3 abaixo:

$$
\begin{gathered}
\mathrm{LO}=\mathrm{RB}-\mathrm{CF}-\mathrm{CV} \\
G A O=1+\frac{C F}{L O}
\end{gathered}
$$

Segundo Silva (2007) a Receita Bruta refere-se à receita das vendas e serviços; Lucro Operacional é o valor da Receita de vendas líquida menos todas as despesas; Ponto de Equilíbrio refere-se ao volume de vendas necessário para cobrir todos os custos fixos e variáveis da empresa e; o Grau de Alavancagem Operacional refere-se ao grau de capacidade que tem uma empresa de aplicar os recursos do seu lucro operacional.

\section{RESULTADOS}

\section{Diagnóstico da Situação dos Resíduos de Galhadas}

A partir das informações obtidas por meio de entrevistas na Secretaria de Infraestrutura e Serviços Públicos, do município de Palmas (TO), os serviços de coleta dos resíduos de poda, roçagem e varrição, são realizados por empresa terceirizada pela Prefeitura Municipal, abrangendo as regiões do Plano Diretor, Taquaralto, Taquari, Aurenys e os distritos de Taquaruçu e Buritirana, com exceção daqueles gerados em áreas particulares. Ressalta-se que apesar da participação do setor privado na geração de resíduos e na criação de pontos de disposição clandestinos, este estudo refere-se apenas aos resíduos coletados pelas empresas terceirizadas que são de responsabilidade da Prefeitura Municipal de Palmas. E que a estimativa dos resíduos coletados informalmente tornou-se inviável, já que não existe controle por parte do Município. 
De acordo com informações da Secretaria de Infraestrutura e Serviços Públicos, do município de Palmas (TO), verificou-se que a partir do ano de 2013 os resíduos de galhadas que eram antes destinados ao Aterro Sanitário do Município passaram a ser depositados em nova área dedicada exclusivamente para este fim. Atualmente tais resíduos não são segregados, quantificados e/ou reaproveitados. A área destinada para a disposição dos resíduos provenientes de poda de árvores está localizada no Setor Norte de Palmas, que tem como coordenadas geográficas $10^{\circ}$ 09' 10,2" de latitude Sul, $48^{\circ} 20^{\prime} 43,9^{\prime \prime}$ de longitude Oeste, e área de aproximadamente 2,67 hectares, conforme apresentado na Figura 2.

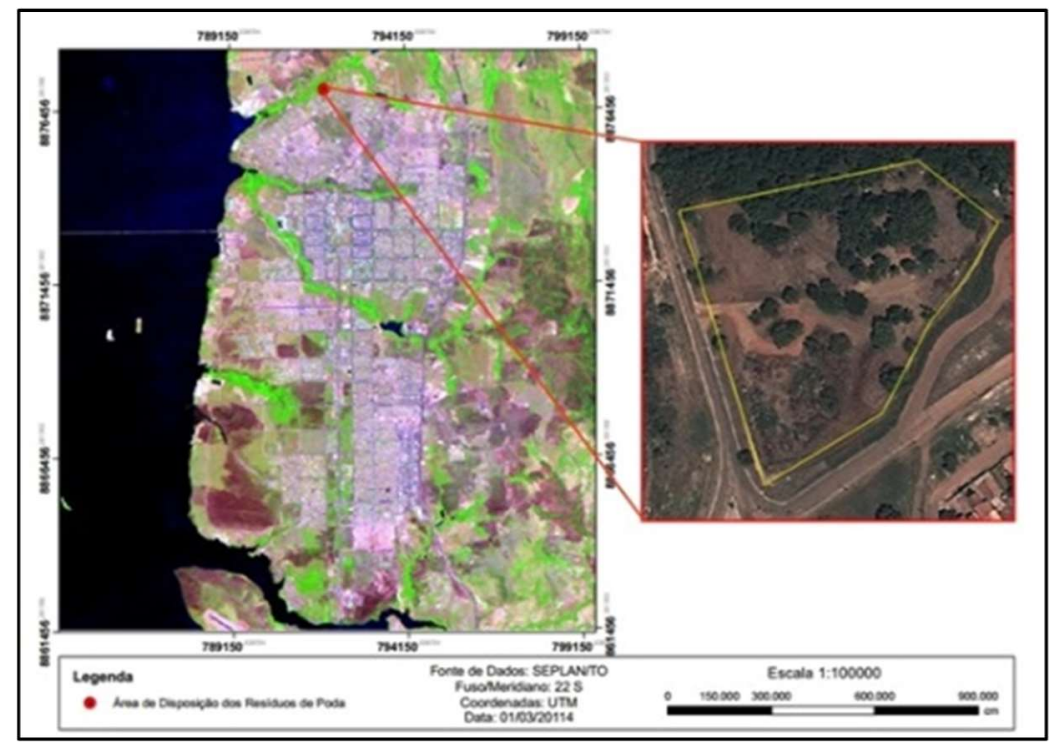

Figura 2: Localização da área de disposição dos resíduos de galhada.

O uso de nova área para disposição ocorreu devido à grande quantidade de resíduos gerados e a entrada indiscriminada de pessoas e veículos particulares dentro do Aterro Sanitário, ocasionando riscos de incêndios e atitudes impróprias. Os resíduos provenientes da poda de arvores não eram depositados dentro das células do Aterro e sim aleatoriamente em áreas livres. Segundo Fernandes et al. (2001) geralmente esses resíduos ficam dispostos nos aterros ou então em áreas específicas, onde ficam estocados e ocasionalmente dão origens a incêndios.

Quanto à possível implantação de uma unidade de beneficiamento para os resíduos os entrevistados, responsáveis pela limpeza pública, foram favoráveis à medida e citaram a existência de projetos futuros para implantação de uma Usina de Compostagem no município. Atualmente os resíduos de galhadas são somente triturados com o objetivo de diminuir o volume, já as madeiras das árvores são recolhidas por empresas de cerâmica, pizzarias e outras indústrias para uso como lenha. Por meio de visita 'in loco' na área foi possível constatar a presença de diversos resíduos comerciais e domésticos, devido à falta de triagem ao se coletar os resíduos da galhada, conforme se observa na Figura 3. Contudo, há uma crescente conscientização por parte dos funcionários no local, que devolvem no mesmo veículo os resíduos inadequados para que recebam a destinação correta. 


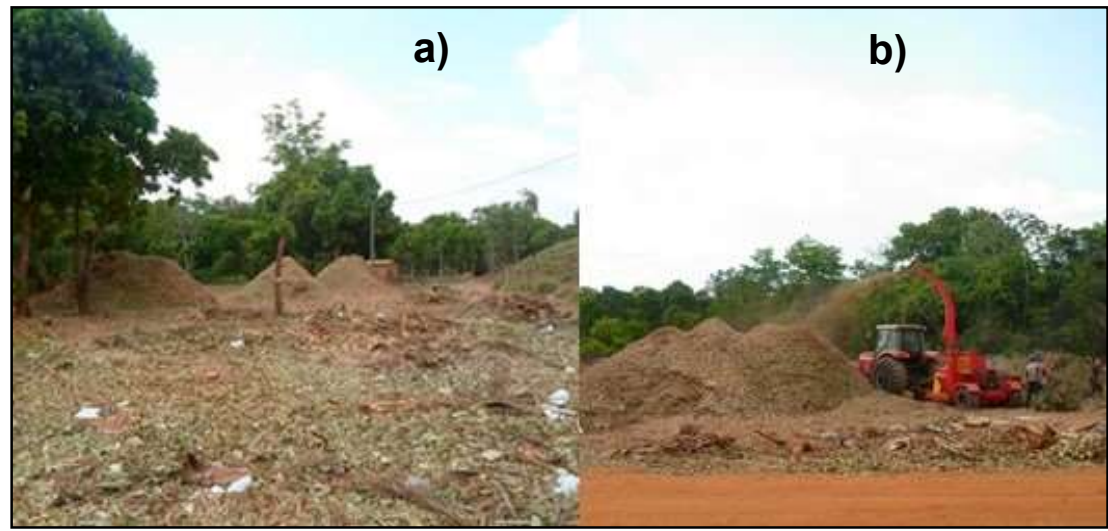

Figura 3: Área de disposição do resíduo da galhada. Presença de lixo (a) e trituração do resíduo (b).

Quanto a realização dos serviços foi identificada 2 (duas) empresas prestadoras de serviço de limpeza urbana no ano de 2013, contratadas por um período de 6 (seis) meses cada. Mensalmente os Serviços de coleta e o transporte de galhadas custam cerca de $R \$ 144.500,00$ mensais e $\mathrm{R} \$ 1.734 .000,00$ anuais, o equivalente a $12 \%$ do valor total dos Serviços Gerais de Limpeza Pública, sendo o terceiro serviço de limpeza que mais custa ao município de Palmas TO, depois dos serviços de limpeza e varrição manual (31\%) e coleta de resíduos domiciliares, comerciais e outros $(27 \%)$.

\section{Estimativa da Produção de Galhadas}

Por meio do quantitativo dos resíduos depositados no Aterro Sanitário, referentes aos anos de 2008 a 2012, a produção dos resíduos de galhada equivale em média a 1301 ton/ano, 108 ton/mensais e 3,61 ton/dia. A produção média per capita dos resíduos de galhada é de 0,02 $\mathrm{Kg} / \mathrm{hab} / \mathrm{dia}$. Considerando custo anual dos serviços de coleta e transporte de $\mathrm{R} \$ 1.734 .000,00$, estima-se um valor de aproximadamente $\mathrm{R} \$ 1332,82$ por cada tonelada coletada desse resíduo. Lembrando que o Aterro Sanitário quantifica os resíduos de todos os veículos que entram e depositam no mesmo, incluindo veículos particulares, sendo assim a coleta desses resíduos custam ao município mais que $\mathrm{R} \$ 1332,82$ por tonelada. Sendo que os resíduos domésticos em Palmas (TO) correspondem a $90 \%$ do total anual e os resíduos de galhada a cerca de $2 \%$. Estima-se que no ano 2014 sejam produzidos 8396,17 ton/ano e 23 ton/dia de galhadas

Conforme se visualiza na

\begin{tabular}{|c|c|c|c|c|}
\hline $\begin{array}{l}\text { Tipo } \\
\text { de Usina }\end{array}$ & Equipamentos Industriais & $\begin{array}{l}\text { Qu } \\
\text { antidade }\end{array}$ & $\begin{array}{l}\text { Custo } \\
\text { Unitário (R\$) }\end{array}$ & $\begin{array}{l}\text { Custo } \\
\text { Total (R\$) }\end{array}$ \\
\hline \multirow{4}{*}{$\begin{array}{l}\text { Comp } \\
\text { osto }\end{array}$} & Picador de disco modelo & 1 & $85.000,00$ & $\begin{array}{l}85.000,0 \\
0\end{array}$ \\
\hline & Revolvedor de Compostagem & 1 & $50.000,00$ & $\begin{array}{l}50.000,0 \\
0\end{array}$ \\
\hline & Motosserras & 2 & $2.377,40$ & $4.754,80$ \\
\hline & Total & & & $\begin{array}{l}139.754, \\
80\end{array}$ \\
\hline \multirow{4}{*}{$\begin{array}{l}\text { Brique } \\
\text { tes }\end{array}$} & Picador de disco modelo & 1 & $85.000,00$ & $\begin{array}{l}85.000,0 \\
0\end{array}$ \\
\hline & Redler de entrada & 1 & $36.000,00$ & $\begin{array}{l}36.000,0 \\
0\end{array}$ \\
\hline & Chupim do secador & 1 & $24.500,00$ & $\begin{array}{l}24.500,0 \\
0\end{array}$ \\
\hline & Secador tambor B 20000 & 1 & $319.000,00$ & 319.000 \\
\hline
\end{tabular}




\begin{tabular}{|c|c|c|c|c|c|}
\hline & & \multirow[b]{2}{*}{1} & \multicolumn{3}{|c|}{00} \\
\hline & Chupim da briquetadeira & & $18.000,00$ & 0 & $18.000,0$ \\
\hline fornalha & Sistema automático de alimentação da & 1 & $49.000,00$ & 0 & $49.000,0$ \\
\hline & Silo/dosador aéreo da briquetadeira & 1 & $32.000,00$ & 0 & $32.000,0$ \\
\hline & Briquetadeira B 115/220 & 1 & $238.100,00$ & 00 & 238.100, \\
\hline & Motor principal da briquetadeira (100 CV) & 1 & $17.000,00$ & 0 & $17.000,0$ \\
\hline & Quadro de comando da briquetadeira & 1 & $16.900,00$ & 0 & $16.900,0$ \\
\hline & Total & & & 00 & 835.500, \\
\hline
\end{tabular}

1 a curva de crescimento da produção de galhadas e a linha de tendência logarítmica o crescimento da produção de galhada é nivelado ao longo do tempo pela área espacial fixa, ou seja, o espaço físico do município. A curva logarítmica melhor se ajusta para taxas de alteração onde os dados aumentam ou diminuem rapidamente e depois se nivela. Contudo, o valor de coeficiente de correlação $\left(R^{2}\right)$ em 0,6 não confirma uma relação de segurança quanto a essa tendência de crescimento e possível estabilização na produção de galhadas.

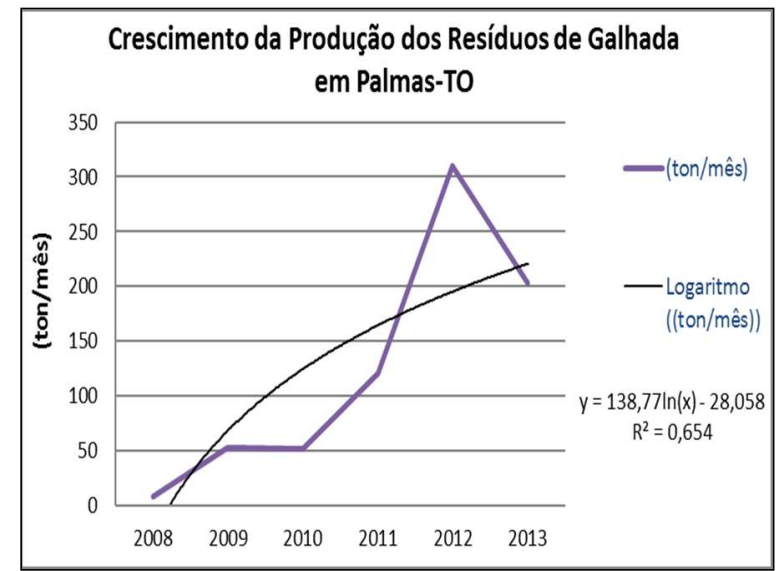

Gráfico 1: Crescimento da produção dos resíduos de galhada de Palmas (TO).

Fonte: adaptado de Secretaria de Infraestrutura e Serviços Públicos de Palmas (TO) (2014).

\section{Análise Técnico-Econômica das Alternativas de Tratamento}

Foi efetuada uma análise técnico-econômica para a implantação de uma fábrica de compactação de resíduos (briquetagem) e uma usina de compostagem, dos resíduos de poda de Palmas (TO). Neste desenvolvimento foi analisado: o regime de trabalho; a capacidade de produção de acordo com a quantidade de resíduos; o investimento inicial para a capacidade de produção; as estruturas de custos operacionais (fixo e variáveis) e; os indicadores técnicoeconômicos de cada fábrica. O estudo baseou-se em dados reais disponibilizados pela SEISP e pelo fornecedor dos equipamentos. Nos cenários não estão inseridas taxas e impostos sobre a produção.

\section{Capacidade Instalada de Produção}


O modelo dos equipamentos foi escolhido de acordo com a produção de galhadas do município, já que a geração de resíduos é estimada 8396 t/ano e 23 ton/dia para o ano de 2014. Atendendo um total de 2112 horas de trabalho anuais a capacidade de processamento foi adequada para cada situação, ou tipo de tratamento. Assim tem-se 3,97 ton/hora de resíduos a serem processados. O modelo da briquetadeira foi selecionado de acordo com a capacidade máxima de produção fornecida pelo fabricante nacional, com processamento de $2,8 \mathrm{t} / \mathrm{h}$ de resíduos. Para a Usina de Compostagem é necessário um equipamento de trituração com capacidade para $4 \mathrm{t} / \mathrm{h}$. O modelo de triturador de galhadas tem capacidade para atender maior volume que o produzido. Os preços dos equipamentos são apresentados na Tabela 1, conforme cotações realizadas junto ao fabricante nacional em 2014.

Tabela 1: Preço dos equipamentos para briquetagem e compostagem.

\begin{tabular}{|c|c|c|c|c|}
\hline Tipo de Usina & Equipamentos Industriais & Quantidade & Custo Unitário (R\$) & Custo Total (R\$) \\
\hline \multirow{4}{*}{ Composto } & Picador de disco modelo & 1 & $85.000,00$ & $85.000,00$ \\
\hline & Revolvedor de Compostagem & 1 & $50.000,00$ & $50.000,00$ \\
\hline & Motosserras & 2 & $2.377,40$ & $4.754,80$ \\
\hline & Total & & & $139.754,80$ \\
\hline \multirow{11}{*}{ Briquetes } & Picador de disco modelo & 1 & $85.000,00$ & $85.000,00$ \\
\hline & Redler de entrada & 1 & $36.000,00$ & $36.000,00$ \\
\hline & Chupim do secador & 1 & $24.500,00$ & $24.500,00$ \\
\hline & Secador tambor B 20000 & 1 & $319.000,00$ & $319.000,00$ \\
\hline & Chupim da briquetadeira & 1 & $18.000,00$ & $18.000,00$ \\
\hline & Sistema automático de alimentação da fornalha & 1 & $49.000,00$ & $49.000,00$ \\
\hline & Silo/dosador aéreo da briquetadeira & 1 & $32.000,00$ & $32.000,00$ \\
\hline & Briquetadeira B 115/220 & 1 & $238.100,00$ & $238.100,00$ \\
\hline & Motor principal da briquetadeira (100 CV) & 1 & $17.000,00$ & $17.000,00$ \\
\hline & Quadro de comando da briquetadeira & 1 & $16.900,00$ & $16.900,00$ \\
\hline & Total & & & $835.500,00$ \\
\hline
\end{tabular}

Para implantação de uma usina são necessários gastos com instalações industriais como eletricidade, água, telefone, entre outras. Estima-se o custo dessas instalações em $10 \%$ do valor do maquinário e equipamento conforme adotado por Felfli et al. (2004), Silva (2007), e Gomes e Pimenta (2010). Para a aquisição de máquinas, móveis e materiais de escritório foi estimado um investimento de $\mathrm{R} \$ 5.000,00$ para Usina de Briquetes e $\mathrm{R} \$ 10.000,00$ para Usina de Compostagem considerado a maior demanda por ferramentas, como enxadas e pás, para o tratamento das leiras de compostagem.

Quanto a Construção Civil o custo médio por metro quadrado é de $\mathrm{R} \$ 965,35$, referente ao material e à mão-de-obra na região Norte (IBGE, 2014). Assim, a construção da área de um galpão para Usina de Compostagem com $160 \mathrm{~m}^{2}$ (galpão de estoque e área para equipamentos) resultará em um custo de $\mathrm{R} \$ 154.456,00$. Já para a Usina de Briquetes com um galpão de $300 \mathrm{~m}^{2}$ (galpão de processamento e área de armazenamento do briquete) resultará em um custo de $\mathrm{R} \$$ 289.605,00. A Tabela 2 apresenta o valor total do investimento inicial que deve ser feito para a implantação do projeto e a depreciação anual dos bens. A depreciação dos ativos que é o custo da perda de valor devido ao desgaste, sendo de $10 \%$ para máquinas, móveis e utensílios e 4\% para edifícios, determinados pela Receita Federal do Brasil e adotado em estudos realizados por Felfli et al. (2004), Silva (2007), Farage (2009) e Gomes e Pimenta (2010). 
Tabela 2: Estimativa de investimento inicial para implantação das tecnologias.

\begin{tabular}{llll}
\hline Usina & Investimento & Custos (R\$) & Depreciação Anual \\
\hline \multirow{4}{*}{ Compostagem } & Equipamentos Industriais & $139.754,80$ & $13.975,48$ \\
\cline { 2 - 4 } & Instalação Industrial & $13.975,48$ & $1.397,55$ \\
\cline { 2 - 4 } & Moveis e equipamentos & $10.000,00$ & $1.000,00$ \\
\cline { 2 - 4 } & Edificação Galpão de $160 \mathrm{~m}^{\mathbf{2}}\left(\mathrm{R} \$ \mathbf{9 6 5 , 3 5 / \mathrm { m } ^ { 2 } )}\right.$ & $154.456,00$ & $38.614,00$ \\
\cline { 2 - 4 } & Custo Total & $\mathbf{3 1 8 . 1 8 6 , 2 8}$ & $\mathbf{5 4 . 9 8 7 , 0 3}$ \\
\hline \multirow{3}{*}{ Briquetagem } & Equipamentos Industriais & $835.500,00$ & $83.550,00$ \\
\cline { 2 - 4 } & Instalação Industrial & $83.550,00$ & $8.355,00$ \\
\cline { 2 - 4 } & Moveis e equipamentos & $5.000,00$ & 500,00 \\
\cline { 2 - 4 } & Edificação Galpão de 300 $\mathrm{m}^{\mathbf{2}}\left(\mathrm{R} \$ \mathbf{9 6 5 , 3 5 / \mathrm { m } ^ { 2 } )}\right.$ & $\mathbf{2 8 9 . 6 0 5 , 0 0}$ & $\mathbf{7 2 . 4 0 1 , 2 5}$ \\
\cline { 2 - 4 } & Custo Total & $\mathbf{1 . 2 1 3 . 6 5 5 , 0 0}$ & $\mathbf{1 6 4 . 8 0 6 , 2 5}$ \\
\hline
\end{tabular}

\section{Custos de Manutenção}

Na Tabela 3 é apresentada a potência anual das fábricas Usina de Compostagem e Usina de Briquetes, com consumo de 155316,48 kWh/ano e 446772,48 kWh/ano, respectivamente. A modalidade tarifária para a demanda e consumo de energia elétrica é a Tarifa Verde, com custo de $0,17 \mathrm{R} \$ / \mathrm{kWh}$ (CELTINS, 2014). Esta modalidade tarifária é aquela com tarifa única para a demanda de potência, tensão de fornecimento inferior a $69 \mathrm{kV}$ e demanda contratada igual ou superior a $300 \mathrm{~kW}$ (ANEEL, 2012). Assim o custo anual com energia elétrica corresponde a R\$ $26.403,80$ para Usina de Compostagem e $\mathrm{R} \$ 75.951,32$ para Usina de Briquetes.

Tabela 3: Capacidade produtiva de cada tratamento.

\begin{tabular}{llll}
\hline Usina & Produção Máxima (ton/h) & Potência (kW) & Potencial Anual (kWh/ano) \\
\hline Compostagem & 10 & 73,54 & 155316,48 \\
\hline Briquetagem & 2,8 & 211,54 & 446772,48 \\
\hline
\end{tabular}

Segundo o custo da embalagem adotado por Gomes e Pimenta (2010) e Silva (2007) para cada tonelada se gasta cerca de $R \$ 22,50$, assim estima-se um gasto anual de $R \$ 184.715,79$ para Usina de Compostagem e $\mathrm{R} \$ 130.099,20$ para Usina de Briquetes. As despesas em manutenção são estimadas como $2 \%$ do custo dos equipamentos, e as despesas administrativas como 5\% do total das despesas administrativas (MACHADO, 2002 citado por FELFLI, 2004). Será necessária a locação de um trator do tipo pá carregadeira, para manobro da galhada e carregamento do material triturado. O custo mensal da locação é de $R \$ 24.000,00$ para $200 \mathrm{~h}$, incluindo o operador da máquina. A locação não inclui custo com combustível, considerando o consumo de $20 \mathrm{~L} / \mathrm{h}$ de óleo diesel a $\mathrm{R} \$ 2,49 / \mathrm{L}$, o total anual gasto com combustível é de $\mathrm{R} \$$ $105.177,60$ para Usina de Briquetes e $\mathrm{R} \$ 124.300,80$ para Usina de Compostagem. Na Usina de Compostagem inclui-se o custo com a máquina revolvedora de leiras.

O custo de mão-de-obra deve ser calculado de acordo com nível de atividade de cada Usina. Na Usina de Compostagem o custo da mão-de-obra industrial inclui o pagamento de 8 funcionários, responsáveis por auxiliar no carregamento de galhos e folhas na máquina trituradora, controle e tratamento do composto, operar máquina de revolvimento das leiras, e funcionário administrativo. Para um salário de $\mathrm{R} \$ 724,00$ mensal, o total anual equivale a uma folha de pagamento de $\mathrm{R} \$ 104.256,00$, incluindo-se os encargos sociais e demais benefícios, que foram calculados em aproximadamente $50 \%$ do valor do salário pago. 
$\mathrm{Na}$ Usina de Briquetagem o custo da mão-de-obra industrial inclui o pagamento de 6 funcionários, responsáveis por auxiliar no carregamento de galhos e folhas na máquina trituradora, operar a máquina e logística de briquetes, e funcionário administrativo. $O$ total anual equivale a uma folha de pagamento de $R \$ 78.192,00$, incluindo-se os encargos sociais e demais benefícios. A Tabela 4 apresenta a estrutura de custos operacional e o custo unitário da produção da tonelada de briquetes e composto.

Analisando os custos anuais (fixos e variáveis) envolvidos na fabricação dos briquetes e do composto orgânico, o custo unitário para fabricação de 1 (uma) tonelada de composto é cerca de $\mathrm{R} \$ 88,74 /$ ton e do briquete é $\mathrm{R} \$ 101,29 /$ ton. O valor do investimento inicial não está incluso nos custos anuais. Conforme estudos realizados por alguns autores o custo específico para a produção de briquete de madeira é de cerca de $\mathrm{R} \$ 162,54 /$ ton em São Paulo-SP (Silva, 2007), R\$ 62,05/ton em Natal (RN) (GOMES \& PIMENTA, 2010), e R\$119,71/ton segundo Felfli et al. (2004).

Tabela 4: Estrutura de custos operacional projetado para o tratamento de 8386,2 ton/ano de resíduos.

\begin{tabular}{lll}
\hline Especificação & Custos (R\$/ano) & \\
\cline { 2 - 3 } & Usina de Compostagem & Usina de Briquetes \\
\hline Custos Fixos: & $\mathbf{8 3 . 1 2 1 , 8 8}$ & $\mathbf{2 0 7 . 5 5 1 , 7 5}$ \\
\hline Depreciação Industrial & $54.987,03$ & $164.806,25$ \\
Locação de Pá carregadeira & $24.000,00$ & $24.000,00$ \\
Manutenção & $2.795,10$ & $16.710,00$ \\
Outras despesas Administrativas & $1.339,75$ & $2.035,50$ \\
\hline Custos Variáveis: & $\mathbf{4 4 1 . 6 7 6 , 3 9}$ & $\mathbf{3 9 1 . 4 2 0 , 1 2}$ \\
\hline Combustível e lubrificantes & $124.300,80$ & $105.177,60$ \\
Energia & $26.403,80$ & $75.951,32$ \\
Eventuais & $2.000,00$ & $2.000,00$ \\
Mão-de-obra & $104.256,00$ & $78.192,00$ \\
Material de embalagem & $184.715,79$ & $130.099,20$ \\
\hline Total Geral & $\mathbf{5 2 4 . 7 9 8 , 2 7}$ & $\mathbf{5 9 8 . 9 7 1 , 8 7}$ \\
\hline Custo Unitário (R\$/t): & $\mathbf{8 8 , 7 4}$ & $\mathbf{1 0 1 , 2 9}$ \\
\hline
\end{tabular}

\section{Análise Técnico-Econômica}

Considerando que no Brasil o preço de venda dos briquetes encontrado foi de $\mathrm{R} \$$ 250,00/ton. (FARAGE, 2009), R\$350,00/ton (GENTIL, 2008) e entre $R \$ 200,00 /$ ton e $R \$$ 300,00/ton. (FILIPPETTO, 2008). O preço de venda do briquete considerado para cálculo foi de $\mathrm{R} \$$ 240,00/ton para uma produção anual de 5.913 t/ano (capacidade da briquetadeira). Para o composto orgânico foi considerado o preço de venda do fertilizante natural de compostagem, observados no mercado nacional. O preço de venda do composto considerado para cálculo foi de $\mathrm{R} \$ 260,00 /$ ton para uma produção anual de 8.396 ton/ano. A Tabela 5 apresenta os valores da Receita Bruta (RB), o Lucro Operacional (LO), o Ponto de Equilíbrio Operacional (PE) e O Grau de Alavancagem Operacional (GAO). 
Tabela 5: Indicadores técnico-econômicos das alternativas de tratamento.

\begin{tabular}{lllllllll}
\hline Usina & $\mathbf{R} \$ \mathbf{t}$ & $\begin{array}{l}\mathbf{P} \\
\text { (ton/ano) }\end{array}$ & $\begin{array}{l}\text { RB } \\
\text { (R\$) }\end{array}$ & PE (\%) & $\begin{array}{l}\text { LO } \\
\text { (R\$) }\end{array}$ & GAO & $\begin{array}{l}\text { PE } \\
\text { (ton) }\end{array}$ & Contr. (R\$/ton) \\
\hline Composto & 260,00 & $8.396,17$ & $2.183 .004,81$ & 4,77 & $1.658 .206,54$ & 1,05 & 400,79 & 207,40 \\
\hline Briquetes & 250,00 & $5.913,60$ & $1.478 .400,00$ & 19,09 & $879.428,13$ & 1,24 & $1.129,16$ & 183,81 \\
\hline
\end{tabular}

Para a Usina de Compostagem quando é praticado o preço de $\mathrm{R} \$ 260,00 / t$, a receita bruta é de $\mathrm{R} \$ 2.183 .004,81$. A fábrica opera com PE de 4,77\%, logo, o volume de lucro mínimos acontecerá a partir de $4,77 \%$ da produção nominal. Observou-se através do grau de alavancagem operacional, que com um aumento de $10 \%$ no nível de atividades da fábrica corresponderá a um aumento de $10,5 \%$ no lucro operacional. De acordo com o ponto de equilíbrio, a quantidade que a empresa precisa vender para cobrir o custo das mercadorias vendidas, as despesas variáveis e as despesas fixas serão 400,79 toneladas. O valor total das despesas fixas (CF), dividido pelo valor em toneladas do ponto de equilíbrio, obtêm-se a margem de contribuição por tonelada de $\mathrm{R} \$$ $207,40 /$ ton.

Agora para a Usina de Briquetes quando é praticado o preço de $\mathrm{R} \$ 250,00 /$ ton, a receita bruta é de $\mathrm{R} \$ 1.478 .400,00$. A fábrica opera com PE de 19,09\%, logo, o volume de lucro mínimo só acontecerá a partir de 19,09 \% da produção nominal. Observou-se através do grau de alavancagem operacional, que com um aumento de $10 \%$ no nível de atividades da fábrica corresponderá a um aumento de $12,4 \%$ no lucro operacional. A quantidade que a empresa precisa vender para cobrir o custo das mercadorias vendidas, as despesas variáveis e fixas serão 1.129,16 toneladas. A margem de contribuição por tonelada de $\mathrm{R} \$ 183,81 /$ ton. Caso a Prefeitura Municipal de Palmas (TO) mantivesse uma Usina de Compostagem, considerando que o custo anual da coleta dos resíduos de galhada é em média $R \$ 1.734 .000,00$, e a receita bruta para Compostagem de $100 \%$ dos resíduos estimada para o ano de 2014 foi de $\mathrm{R} \$ 2.183 .004,81$, verifica-se que a receita cobriria os custos gastos e ainda haveria um lucro de $R \$ 449.004,81$ ao ano.

\section{CONCLUSÕES}

A análise da situação e gestão atual dos resíduos provenientes da poda, do município de Palmas (TO), mostrou que os mesmos são passíveis de reutilização e aproveitamento, evitando sua disposição no Aterro Sanitário e em áreas impróprias. Bem como, essa gestão dos resíduos se encaminha paulatinamente para um modelo mais adequado.

Por meio da análise da viabilidade técnico-econômica da Usina de Briquetes e da Usina de Compostagem para Palmas (TO), utilizando os resíduos de galhada, conclui-se que tais tratamentos são viáveis economicamente, já que o custo estimado de produção foi de $R \$ 88,74 / t$ para o composto e $\mathrm{R} \$ 101,29 / \mathrm{t}$ para o briquete. Valor este, cerca de 2 vezes menor que o preço de venda, o que torna viável a produção e comercialização dos mesmos. No entanto, quanto aos custos de investimento inicial para implantação percebeu-se que a Usina de Compostagem é mais econômica, com custo cerca 4 vezes menor que para a Usina de Briquetes. Se sugere e se torna 
de suma importância uma análise técnico-econômica incluindo impostos e taxas sobre a produção, além de um diagnóstico aprofundado da perspectiva de mercado para ambos os produtos em Palmas (TO) e região circunvizinha.

\section{REFERÊNCIAS}

ALBUQUERQUE, C. E. C.; ANDRADE, A. M.. Briquetagem - Visão histórica e perspectiva futura. Rev. Floresta e Ambiente. Rio de Janeiro, v.4, p.104-109, 1997.

ASSOCIAÇÃO BRASILEIRA NORMAS TÉCNICAS. Norma Brasileira 10.004, de 30 de novembro de 2004. Estabelece os critérios para Classificação dos Resíduos Sólidos. Rio de Janeiro: ABNT, 2004.

ANEEL. Agencia Nacional de Energia Elétrica. Informações Técnicas: Bandeiras Tarifárias. Brasília: ANEEL, 2012.

ANGELIS, B. L. D.; SAMPAIO, A. C. F.; TUDINI, O. G.; ASSUNÇÃO, M. G. T.; NETO, G. A.. Avaliação das árvores de vias públicas da zona central de Maringá, Estado do Paraná: estimativa de produção de resíduos e destinação final. Revista Acta Sci. Agro, Maringá, v.29, n.1, p.133-140, 2007.

BRAND, M. A.; MUÑIZ, G. I. B.; SILVA, D. A.; KLOCK, U.. Caracterização do rendimento e quantificação de resíduos gerados em serrarias através do balançode materiais. Revista Floresta On-Line, v.32, n.2, p.347259, 2002.

BRASIL. Lei $\mathbf{n}^{\circ}$ 12.305, de 2 de agosto de 2010. Institui a Política Nacional de Resíduos Sólidos; altera a Lei n 9.605, de 12 de fevereiro de 1998; e dá outras providências. Brasília: DOU, 2 Ago 2010.

CASTRO, J. B. H.. Diagnóstico dos serviços de limpeza urbana do Campus Cidade Universitária "Zeferino Vaz" da Universidade Estadual de Campinas. Dissertação (Mestrado) - Universidade Estadual de Campinas, Campinas, 2008.

CELTINS. Companhia de Energia Elétrica do Estado do Tocantins. Tarifas Vigentes. Palmas: CELTINS, 2014.

COSTA, L. E. B.; COSTA, S. K.; REGO, N. A. C.; SILVA JUNIOR, M. F.. Gravimétrica dos resíduos sólidos urbanos domiciliares e perfil socioeconômico no município de Salinas, MinasGerais. Revista Ibero

Americana de Ciências Ambientais, Aquidabã, v.3, n.2, p.73-90, 2012.

CORTEZ, C. L.. Estudo do potencial de utilização da biomassa resultante da poda de arvores para geração de energia: estudo de caso: AES Eletropaulo. Tese (Doutorado) - Universidade de São Paulo, São Paulo, 2011.

CORTEZ, C. L.; GRISOLI, R.; GAVIOLI, F.; COELHO, S. T.; CARMELO, S.. Alternativa sustentável para utilização de resíduos de poda provenientes da manutenção das redes de distribuição de energia elétrica. São Paulo: Centro Nacional de Referência em Biomassa, 2008.

COUTO, L.; MÜLLER, M. D.; SILVA, A. G. J.; NARDOTO, L. J. C.. Produção de pellets de madeira - o caso da Bioenergy no Espírito Santo. Revista Biomassa \& Energia, Viçosa, v.1, n.1, p. 45-52, 2004.

DOURADO, L. C.; JP SILVA, R.. Estudo sobre impacto de volume de lixo em aterros proveniente de podas de árvores e jardins. Revista Ciências do Ambiente On-Line, v.7, n.1, 2011.

FARAGE, R. M. P.. Aproveitamento dos resíduos lignocelulósicos gerados no Polo Moveleiro de Ubá para fins energéticos. Dissertação (Mestrado em Engenharia Ambiental) - Universidade Federal de Ouro Preto, Ouro Preto, 2009.

FELFLI, F. F.; LUENGO, C. A.; ROCHA, J. D.. Briquetes torrificados: viabilidade técnico-econômica e perspectivas no mercado brasileiro. In: ENCONTRO DE ENERGIA NO MEIO RURAL. 5. Anais. Capinas: 2004. 
FERNANDES, F.; BATISTA, G. A.; SOUZA, S. G.; SILVA, S. M. C. P.. Aproveitamento dos resíduos de podas de árvores e capinas do meio urbano para produção de composto. In: CONGRESSO BRASILEIRO DE ENGENHARIA SANITÁRIA E AMBIENTAL. 21. Anais. João Pessoa: ABES, 2001.

FILIPPETTO, D.. Briquetagem de resíduos vegetais: viabilidade técnico-econômica e potencial de mercado. Dissertação (Mestrado) - Universidade Estadual de Campinas, Campinas, 2008.

FREITAS, D. F.. Caracterização de resíduos sólidos domiciliares na cidade satélite do Varjão, Distrito Federal, Brasil. Dissertação (Mestrado em Ciências da Saúde) - Universidade de Brasília, Brasília, 2006

GENTIL, L. V. B.. Tecnologia e Economia do Briquete de Madeira. Tese (Doutorado em Engenharia Florestal) - Universidade de Brasília, Brasília, 2008.

GOMES, K. M. F.; PIMENTA, H. C. A.. Potencialidade da reutilização dos resíduos da madeira para fins energéticos: uma abordagem do ponto de vista da ecologia industrial no APL dos móveis da grande NatalRN. In: Encontro Nacional de Engenharia de Produção. 30. Anais. São Carlos, 2010.

GRIPPI, S.. Lixo Reciclagem e sua História: guia para as prefeituras brasileiras. Rio de Janeiro: Editora Interciência, 2001.

IBAM. Instituto Brasileiro de Administração Municipal. Manual Gerenciamento Integrado de Resíduos Sólidos. Rio de Janeiro, 2001.

IBGE. Instituto Brasileiro de Geografia e Estatística. Censo Demográfico 2010. Rio de Janeiro: IBGE, 2010.

IBGE. Instituto Brasileiro de Geografia e Estatística. Sistema Nacional de Pesquisa de Custos e Índices da Construção Civil. Rio de Janeiro: IBGE, 2014.

IPT/ CEMPRE. Instituto de pesquisas Tecnológicas/Compromisso Empresarial para Reciclagem. Lixo municipal: Manual de Gerenciamento Integrado. São Paulo: CEMPRE, 1995.

JUNIOR, O. F. C.. Produção de Carvão Ativado a partir de Produtos Residuais de Espécies Nativas da Região Amazônica. Dissertação (Mestrado em Engenharia Mecânica e de Materiais) - Universidade Tecnológica Federal do Paraná, Curitiba, 2010.

MELO, A. C. A.; BARROS, M. V. F.; FERNANDES, F.. Diagnóstico da gestão de resíduos sólidos urbanos no município de Rolândia (PR). Rev. Geografia, Londrina, v.20, n.2, p.5-28, 2011.

MORAIS, M. R.; SEYE, O.; FREITAS, K. T.; RODRIGUES, M.; SANTOS, E. C. S.; SOUZA, R. C. R.. Obtenção de briquetes de carvão vegetal de cascas de Arroz utilizando baixa pressão de compactação. Manaus: Universidade Federal do Amazonas, 2007.

MOURA, J. S.; BARROS, R. M.; CALHEIROS, H. C.; TIAGO FILHO, G. L.; SILVA, F. G. B.. Avaliação do processo de compostagem de resíduos urbanos: o caso dos resíduos do restaurante e de poda de um campus universitário. In: CONGRESSO BRASILEIRO DE ENGENHARIA SANITÁRIA E AMBIENTAL. 25. Anais. Recife: UFPE, 2009.

PHILIPPI JUNIOR, A.; AGUIAR, A. O. Resíduos sólidos: características e gerenciamento. Barueri: Manole, 2005.

QUIRINO, W. F.. Poder Calorífico da Madeira e de Resíduos Lignocelulósicos. Revista Biomassa \& Energia, Viçosa, v.1, n.2, 2004.

RODRIGUES, L. D.; SILVA, I. T.; ROCHA, B. R. P.; SILVA, I. M. O.. Uso de briquetes compostos para produção de energia no Estado do Pará. $4^{\circ}$ Encontro de Energia no Meio Rural (AGRENER 2002). Campinas, 2002.

SAIDUR, R.; ABDELAZIZ, E. A.; DEMIRBAS, A.; HOSSAIN, M. S.; MEKHILEF, S. J.. Renew. Sust. Energ. Rev. v.15, n.2262, 2011.

SANTOS, P. S. M.; ROCHA, L. M. R.. Educação ambiental: o destino do lixo urbano em Laranjeiras (SE). In: COLÓQUIO INTERNACIONAL EDUCAÇÃO E CONTEMPORANEIDADE. 4. Anais. São Cristóvão: UFS, 2010. 
SILVA, C. A.. Estudo técnico-econômico da compactação de resíduos madeireiros para fins energéticos. Dissertação (Mestrado em Planejamento de Sistemas Energéticos) - Universidade Estadual de Campinas, Campinas, 2007.

SILVA, M. J. D.; RENOFIO, T. C. Z.; MARGUTT, M. C.. A Reutilização dos Resíduos das Podas de Árvores e o Levantamento Regional dos tipos de Árvores. In: Simpósio Internacional de Ciências Integradas. 4. Anais. Guarujá: Universidade de Ribeirão Preto, 2009.

SOBRAL, J. A.; MAGALHÃES, K. M.. Avaliação operacional da compostagem dos resíduos de poda realizada em Aterro de Resíduos Sólidos da cidade do Recife, PE. In: Jornada de Ensino Pesquisa e Extensão da UFRPE. 9. Anais. Recife, 2009. 